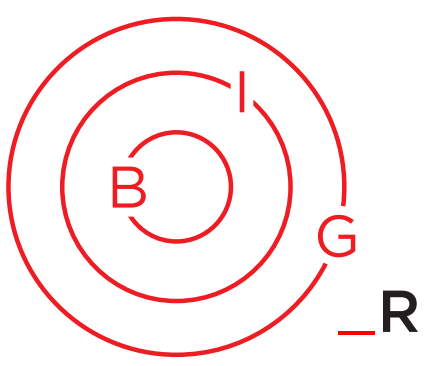

ARTICLE
Borders in Globalization Review

Volume 1, Issue 1 (Fall 2019): 29-42

https://doi.org/10.18357/bigr11201919249

\title{
Mobile Youth and Belonging in the Gulf: A Study of Dubai
}

\section{Sitwat Azhar Hashmi *}

\begin{abstract}
The rapid economic growth in the Gulf Cooperation Council (GCC) region has enticed flocks of expatriates from all over the world to the region in hopes of attaining a better quality of life. These expats often migrate with their spouses and children in tow bringing to light a new challenge for the Arab world: mobile youth. This research aims to find if the journey 'home' (repatriation) plays a role in developing these mobile children's sense of belonging to a 'home', and if so, to which 'home'. In order to do this, the research will conduct a theoretical analysis of these mobile youth born or raised within the Gulf by analysing one-on-one structured interviews through the lens of the theory of belonging, and the study of language and culture. This research concludes that in fact, mobile youth build their sense of belonging in relation to multiple 'homes' and not just to their 'adopted' or 'parental' home.
\end{abstract}

Nevertheless I long - I pine, all my days -

to travel home and see the dawn of my return.

And if a god will wreck me yet again on the wine-dark sea,

I can bear that too, with a spirit tempered to endure.

Much have I suffered, labored long and hard by now

in the waves and wars. Add this to the total -

bring the trial on!

- The Odyssey, Homer

\section{Introduction}

Home. Belonging. Identity. These are some of the most common words one encounters in every migrant's story. Words that appear so simple but prove rather complex upon closer examination. Words that change and take shape with the migrant through the duration of their journey as the migrant simultaneously changes through them. Home no longer remains a physical, still, entity. It comes to life through the journey, stretching and expanding from the physical into the outward - it becomes mobile; grounded yet changing (Ralph \& Staeheli 2011, 518; Zhang 2004, 104). Such are the homes of the children born to the life of mobility; children who involuntarily cross borders at birth or preadolescence, forming identities and a sense of belonging around cultures, languages and places that are not a part of their 'home'. What happens then, when such individuals are forced by their circumstances to go back to their perceived origins - to go 'home' leaving behind their adopted 'home'?

The rapid economic growth in the Gulf Cooperation Council (GCC) ${ }^{1}$ region has enticed expatriates from all over the world to the region in hopes of attaining a better quality of life. Naturally then, these expats often migrate with their spouses and children in tow bringing to light a new challenge for the Arab world: mobile youth. Though the migration of expats in

\footnotetext{
* Sitwat Azhar Hashmi, MSc Political Science (Leiden University), is currently working in The Hague at the United Nations International Residual Mechanism for Criminal Tribunals. Contact: sitwatazharhashmi@gmail.com
} 
Borders in Globalization Review | Volume 1 | Issue 1 | Fall 2019

Hashmi, "Mobile Youth and Belonging in the Gulf"

the region is not new, and has garnered a fair bit of academic interest around the topic, yet, arguably the most vital aspect of the expatriates' journey in the region remains overlooked in research - the final phase of an expatriate's journey: repatriation. The process of repatriation is especially made more complicated when it centers itself around children who not only migrate involuntarily but are also made to repatriate involuntarily (usually by the will of their parents).

\section{Definition}

Due to a sharp increase in transnational identities around the world, migration studies today provide us with several theoretical lenses to analyse the economic, political, and social ties forged by migrants across various borders. Scholars like Rouse (1991), Guarnizo (1997), and Kyle (2000) believe that a mobile relationship between 'man' and 'soil' provides a mobile migrant with 'bifocality', 'dual frame of reference', or 'bionationality', all of which are created and maintained by the migrant himself. Their host nations and nations of their 'origins' create a push and pull force of cultures, traditions, and everyday life practices that cause the migrant to be influenced by both places instead of just one. Thus, making it difficult for them to accept a single place (soil) as their absolute 'home'.

This interpretation of home challenges the previously held perceptions of 'home' as a bounded and still presence. Instead, it portrays 'home' as a mobile, unclear and often, chaotic entity. Therefore, as migrants travel, their identities are caught up in a continual push and pull of their 'new' and 'old' worlds, leading to the formation of their composite belonging to multiple 'homes'.

Rooted in these definitions is our concept of 'home' in relation to the mobile youth of the Gulf, or more specifically, Dubai, the focus of this study. As they trek through countries, they station and un-station themselves several times (often across continents) throughout their lives. Often times, they stop and ponder over homes lost and built and lost and re-built over time. Pondering still, over building a home, or journeying home only to find that home, like them, has grown and evolved and changed through time, through them, and through their journey. 'Home' then becomes a mobile being, alive like the self. It shifts, grows, and changes with the migrant. In this paper, a distinction between such 'homes' will be made to avoid confusion. The host nations of these mobile youth will be referred to as being their 'adopted homes', whilst the nations of their 'origin,' or their parents' home, more specifically, will be referred to as being their 'parental homes'.

\section{Aims \& Hypothesis}

This research aims to find if the journey 'home' (repatriation) plays a role in developing mobile youth's sense of belonging to a 'home', and if so, to which 'home'. It hopes to find whether repatriation increases the mobile children's sense of belonging to their parental 'home' over their adopted 'home', or vice versa, or possibly both. It hopes to explain why mobile youth face difficulties when forming a sense of belonging and rootedness towards a single state due to the transnational nature of their identities. The research would also like to uncover the manner in which these youth form their sense of belonging to a 'home' in the first place, as they live in a continuous state of nostalgia for their origins, while searching for a 'home'. In short, this research hypothesizes that in fact, mobile youth build their sense of belonging in relation to multiple 'homes' and not just to their 'adopted' or 'parental' homes.

\section{Research Design}

This research seeks to uncover a link between repatriation and mobile youth's formation of their sense of belonging to a 'home'. To do this, the research will be conducted as a theoretical study of two independent groups of mobile youth. Group A, will consist of mobile youth currently residing in the Gulf who have at least made one journey home since they started living in the Gulf. They must have had resided in the region since the ages of 0-10 years, or may have been born there. Group B, on the other hand, will consist of mobile youth who once resided in the Gulf and have either repatriated to their parental 'homes' or migrated to another country outside of the Gulf. They must also have had been residing in the region since the ages of 0-10 years, or may have been born there.

\section{The Sample}

To further control variables and to ensure as reliable and credible a result as possible, all participants were confirmed to have been currently residing or to have had previously resided in the United Arab Emirates (UAE), specifically in Dubai, and that they all shared similar cultural backgrounds as their 'origin' with the exception of only three (further discussed under the 'Identification' sub-section). Furthermore, only participants between the ages of 18 years and up were selected for this research. It is also important to note that all participants taking part in this research shared similar educational and socio-economic backgrounds, i.e. they all came from expatriate families and international schooling. It was also ensured that any repatriations that took place within the participants of Group A and Group B were not state-endorsed, rather done so voluntarily or undertaken due to the wishes 
of their parents (guardians). All interviews were conducted in English only, and the questions of the interviews were kept from the participants until the commencement of the interview itself, where they were made aware of the questions as they were being interviewed.

\section{Case Selection}

Dubai is a coastal territory of the UAE, located on the southeast coast of the Persian Gulf that shares a southern border with Oman (Figure 1). I have selected Dubai as my case study as it is part of one of the most progressive and developed countries in the Gulf that also currently holds the world's strongest passport. Dubai is also highly metropolitan and as such, is a melting pot of ethnicities, races, nationalities, religions, and cultures. Its total population currently stands at over 1.6 million, and is expected to reach 3 million by 2030. Across the UAE, the total of Emirati citizens only make-up for less than $20 \%$ of the total population; $83 \%$ of the population consists of expatriates from Asia, Africa, Australia, Europe and North America. This, according to the International Organization for Migration, makes Dubai the world's most cosmopolitan city in the entire world.
Dubai, being one of UAE's seven emirates, ${ }^{2}$ is also a compelling study in the context of migration due to the implementation of their unique citizenship and naturalization laws in the region. UAE citizenship may be acquired by virtue of law, or through citizenship or naturalization procedures as set by law according to the Federal Law No.17 of 1972 on Nationality and Passports, amended by Federal Law No. 10 of 1975 and Decree Law No. 16 of 2017. One may apply for naturalization at the General Directorate of Residency and Foreigners Affairs (GDRFA) of their relevant emirate (2019).

However, the naturalization avenues available to expatriate families, akin to those addressed in this paper, are minimal as the Emirati naturalization laws are heavily based around the lawful union of a foreigner to a national through the act of marriage. These naturalization applications are reviewed and processed by an advisory committee referred to as the Federal Authority for Identity and Citizenship (ICA), consisting of seven members representing each of the seven emirates of the UAE (2019).

It is important to note that in the broader context of the Gulf citizenship laws, citizenship is regarded as

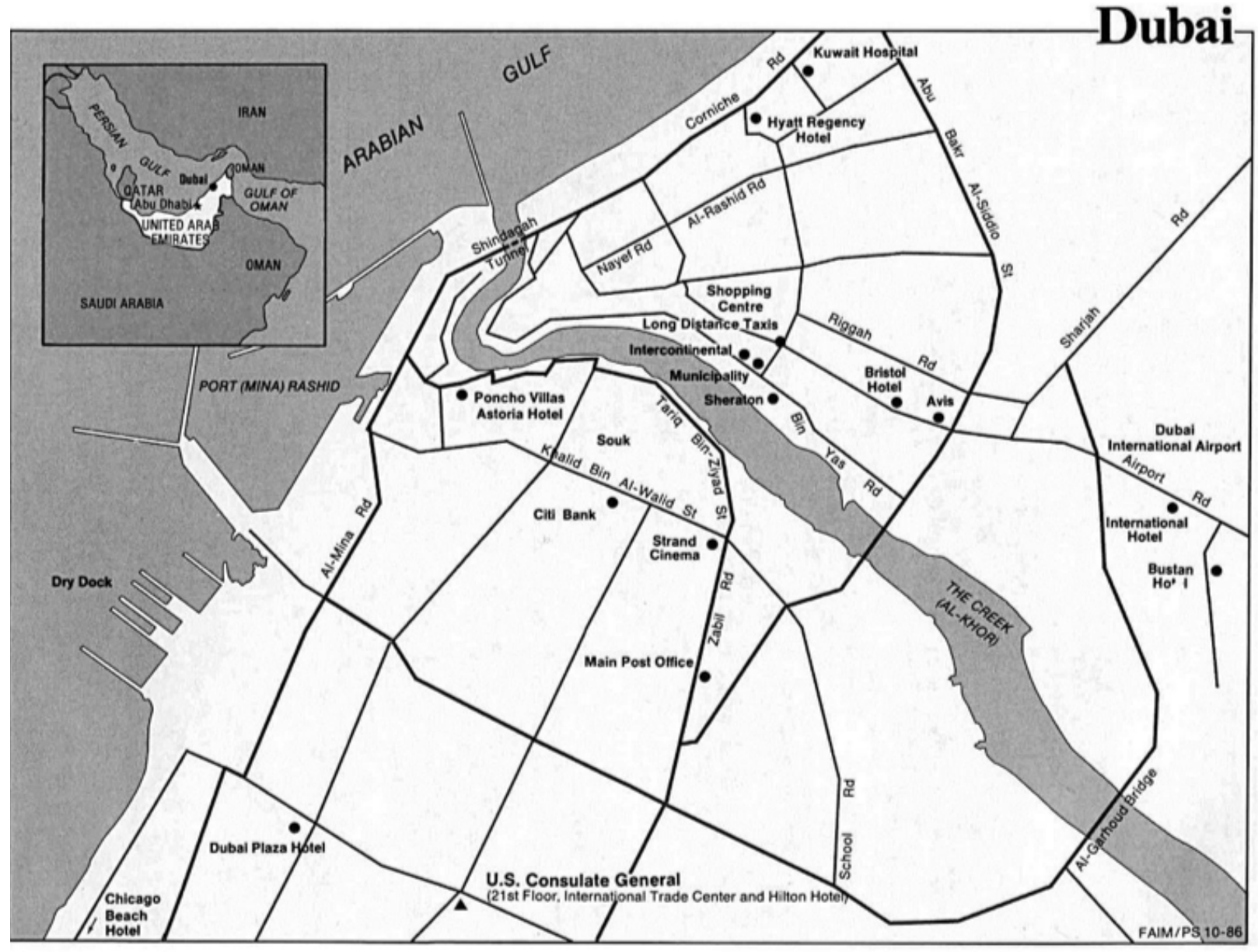

Figure 1. Map source: University of Texas Library, Perry-Castañeda Library, Map Collection 
Borders in Globalization Review | Volume 1 | Issue 1 | Fall 2019

Hashmi, "Mobile Youth and Belonging in the Gulf"

a privilege (a gift) and not as a right of its residents. The UAE is no exception to this. Under the citizenship and naturalization laws of the UAE, a foreigner born in the UAE to foreign parents has no right to the Emirati nationality. The only exceptions to this are the following:

i. A child born in the UAE whose origins and parents are unknown may have the right to attain an Emirati nationality, or

ii. In accordance to a decree issued by the President of the UAE, an 'exceptional' migrant may be granted the Emirati nationality (given that the 'exceptional' migrant is willing to renounce their existing nationalit(ies)).

Given these facts, Dubai would make for a decidedly interesting case study on transnational identities in a region that is currently not being studied or researched for the effects of repartition on its transnational residents.

\section{Method, Data Collection \& Operationalization}

The first step in data collection was to review secondary articles from various databases to scour prior research on the themes of repatriation in relation to the formation of a sense of belonging to a 'home'. This step identified theories of belonging that helped to perform a theoretical analysis of the data gathered in the second step.

In the second step, information was gathered through interviews. The method utilized one-on-one interviews, entirely conducted via Skype video calls (with the exception of one that was conducted only as a skype audio call) where the reactions, expressions, body language and the tone of voice of the participants were clearly recorded and observed. These interviews were then archived through screen recording software, as well as audio recording devices, and were then transcribed. First in short-hand as the interview took place, and later transcribed digitally in full. The method utilized was open-ended structured questions in order to generate relevant information without losing track of the conversation and allowing interviewees to elaborate upon their answers. Furthermore, previously scripted questions and structured interviews helped to establish constant variables during the interviewing process so that the interviews could then be compared and contrasted with one another in a fair and credible manner (Schaffer 2006, 187).

The interviews also looked to engage the participants in a conversation where the participants were given the opportunity to express themselves fully in terms of language. The language itself will be looked at and analyzed in its use as well as its context so as to not take anything away from its meaning. In order to motivate the participants to share their opinions freely, use of judgement questions was made as judgement questions require the interviewee to share their opinions and make clear judgements that help to reveal their position on a topic at hand. Furthermore, elaboration prompts, example prompts, cultural logic questions and restatement questions were also largely utilized to encourage the participants to give more information or to clarify their position with examples and explanations without trying to steer their opinion or position on the matter. Additionally, direct questions were also utilized throughout the duration of the interview to ensure that the participants fully understood what it was that was being asked of them in the interview (Schaffer 2006, 187). Typically, the interviews lasted somewhere between 30 and 45 minutes.

Furthermore, all participants of the research are referred to with pseudonyms in this paper to protect their identity and confidentiality since the topic concerns sensitive, personal, and at times controversial, data. Their pseudonyms will be, Leyla, Arjun, Lulu and Noha, under Group A; and Basil, Remy, Hachim, and Fynn under Group B.

\section{Literature Review: The Politics of Belonging}

There are two main schools of scholarly thought on the topic of belonging, or more specifically, on the formation of the sense of belonging towards a physical and metaphorical 'home' among migrants in relation to repatriation. Both camps acknowledge repatriation as being a fundamental step in an expatriate's journey when assessing their formation of a sense of belonging to a place. They also view 'home' as a mobile being that shifts, grows, and changes with the migrant throughout their journey. Despite these similarities, the two camps disagree in a number of other ways when interpreting the effects of repatriation in relation to a migrant's sense of belonging to a 'home', parental or adopted.

The first camp of scholars understands repatriation as being not only the most important part of an expatriate's journey but also see it as being the most traumatic part of an expatriate's journey (Chiang, et al. 2017, 2). They see the sense of belonging as being an emotional attachment that not only makes you feel like a part of the community but also makes you feel safe as a result of belonging to that community (Yuval-Davis 2006, 197). As such, repatriation becomes the process through which mobile youth are separated from their familiar surroundings and thrown into the unknown. This results in a loss of the mobile youths' sense of belonging towards their parental 'home' while simultaneously increasing their sense of belonging towards their 
adopted 'home'. Studies have shown that individuals shape their identities and sense of belonging through the process of "being and becoming and belonging and longing to belong" (Yuval-Davis 2006, 202), thus, constantly changing and adapting to the culture and social norms of their adopted 'home' in the pursuit of wanting to fit-in. Due to this, repatriation then makes the individuals aware of the loss of the familiar and aware of their own foreignness that is created due to them assimilating in their adopted 'home' country (to become a part of the 'us'), making them the other ('them') in their parental 'home' country. Thus, severing the sense of belonging towards the parental 'home'.

Furthermore, related to the previous position of the camp, belonging is perceived as being a performative act undertaken by the migrant within a specific social and cultural space where certain traditions and practices are repeated to form a linkage between the individual and the collective behavior (community) to form identity narratives and construct attachments to the community (Yuval-Davis 2006, 203). Thus, this camp of thought believes that it is due to this emotional component of feeling like belonging to a place that leads to reverse culture shock among repatriates upon repatriation. That is, when the emotional components of a migrant's identity are threatened by the social and cultural space of their parental 'home', the repatriate feels less secure amidst the unfamiliar. Thus, once again being made aware of their own strangeness within their assumed social and cultural space of origin (Yuval-Davis 2006, 202). This loss of ownership over their presumed origin leads to the migrant losing their sense of belonging to their parental 'home' as a consequence.

The model and theory of belonging under this camp, formulated by Paul Jones and Michał Krzyzanowski (2008), further explains this by describing the relationship between identities, attachment and belonging (Figure 2). They argue that the migrant forms their identity in two parts, internal and external. Internally, the migrant constructs an identity through the "(re)presentation" of their self and through positioning themselves in relation with others. Externally, the migrant is able to construct an identity through the channels made available by the "institutional gatekeepers" who put in place a formal threshold criterion that outlines the requirements for gaining membership to a group through formal methods (like citizenship requirements) or through informal methods (such as "symbolic" social prerequisites of the day- to-day life) (2008, 44-45). The model further explains that it is through the relationship between attachment and belonging (represented in the figure through arrows) which helps to identify how individuals become part of collective identities. Therefore, when there is a lowered sense of attachment (i.e. lessened number of arrows to match the lessened feelings of attachment) to a social and cultural sphere (in this case that of the parental (home'), the expatriate then feels a lowered sense of belonging towards that sphere $(2008,46)$.

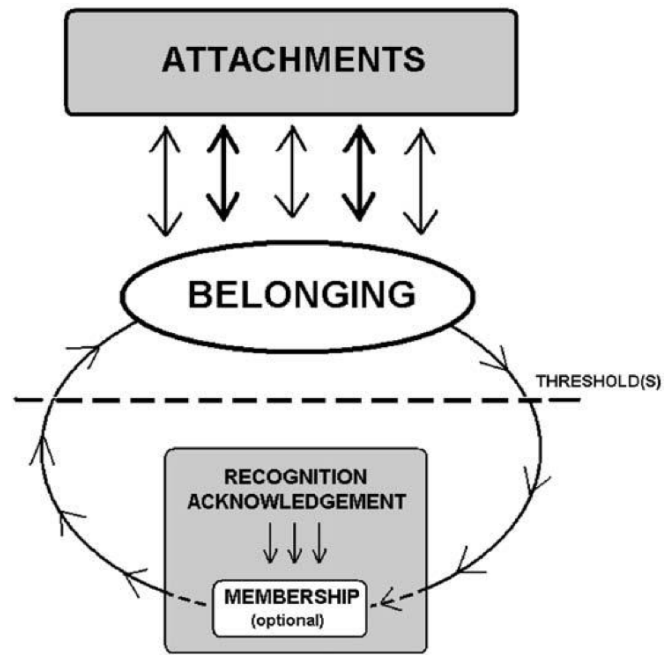

Figure 2. Source: Jones \& Krzyzanowski 2011, 45.

In addition to that, this model also helps to show how beyond the threshold criteria exists a second (informal) set of gatekeepers: the people. Without the recognition and acknowledgement of the repatriate by the collective identity (the community), the repatriate is unable to gain full 'membership' to it. Thus, upon repatriation mobile youth fail to gain this recognition in the parental 'home' due to having had severed their attachments to it in order to belong to their adopted 'home'. In so doing, they lose 'membership' to their parental 'home's' collective identity which directly affects their sense of belonging to it as the relationship between 'membership' (formal or informal) and belonging is recurrent.

Additionally, this loss of a sense of belonging that the migrant experiences due to attachment is made worse when perceptions of home are fantasized (unrealistic attachments) by the repatriate as they learn of their origins ('home') through biased sources (i.e. parents, grandparents, etc.) who recall a nostalgic version of the parental 'home'. It is only upon repatriation that it dawns on the migrant that the 'home' from their memories no longer exists and will never exist as it was only ever a snapshot of the past. It is the realization that the attachments they tied to a sense of belonging were rooted in a false attachment. This loss of 'home' as it had been remembered then, Edward Said (2001) would say, is what makes the repatriate aware of their state of living in a form of exile as they no longer have a 'home' to return to causing a further loss in their sense of belonging to it. The individual is left expelled from their 'home', dreaming of a lost 
Borders in Globalization Review | Volume 1 | Issue 1 | Fall 2019

Hashmi, "Mobile Youth and Belonging in the Gulf"

paradise that no longer exists due to the shift in space and time.

Finally, scholars under this camp also cite growth and social and economic developments as additional reasons that may contribute to a loss of belonging among migrants upon repatriation. They argue that the expatriate is unaware of the ways in which $\mathrm{s} / \mathrm{he}$ changes over the duration of his expatriation and that it is only upon repatriation that the expatriate comes to realize just how much they have changed versus how little their parental 'home' has changed (Chiang et al., 2017, p.17-18). This discrepancy paired with the expatriate returning to a country that is less economically and socially developed than the one they are returning from, can exacerbate feeling the loss of one's sense of belonging to the parental 'home' as it no longer provides the emotional, social or economic comfort required for the migrant to feel at 'home' (Chiang et al. 2017, 15-16).

The second camp of scholars also agrees that repatriation is an important part of an expatriate's journey, however, they differ on their inferences of the effects of repatriation on the migrant. Firstly, they believe repatriation can give an individual an increased sense of belonging to their parental 'home' over their adopted 'home' as they enjoy more legal rights in their parental 'home' over their adopted 'home' as they are elevated to the status of a citizen (gaining full formal and informal membership) instead of being a mere expatriate or a migrant. This not only gives ease of access to the individual in terms of opportunities (social and economic), it also gives them an increased sense of self-esteem as the shame and burden of being a migrant, a foreigner, and a 'thief', in another country (their adopted 'home') is lifted off of their shoulders (Ralph \& Staeheli 2011, 55; Minh-ha 2010, 30). Thus, making the individual feel more at home in their parental 'home' country over their adopted 'home' country through the process of making them feel whole. In fact, many studies show that if an individual maintains some form of link with their parental 'home' whilst staying in their adopted 'home' through the means of communication, travel, or materials and objects, it becomes an "adaptive response" towards the hostile nature of the adopted 'home' towards migrants - a reality not lost on most migrants (Ralph \& Staeheli 2011, 55). That is, even while away from their parental 'home', a link to it (no matter how deep) serves the purpose of increasing their sense of belonging to it and provides a sense of comfort in an otherwise unwelcoming setting.

Scholars under this camp recognize that for many returnees their parental 'homes' represent their ancestral lands and a stable and fixed identity. However, this idealization of the parental 'home' soon fades away as the individual comes to the realization that their self-identities have turned both into the outsider and insider of their parental 'home' (Ralph \& Staeheli 2011, 522-523). This discrepancy in the individual's identity is precisely what it means to be multicultural. Migrants, through repatriation claim ownership of more than one social and cultural sphere where they are able to navigate between the 'old' and the 'new' with ease (Ralph \& Staeheli 2011, 521). Scholars in this camp do not view this ability of cultural and social code-switching as a negative effect of repatriation, in fact, they view it as a good thing. They believe a migrant's identity is considerably strengthened and their ties to multiple places, deepened. Thus, resulting in an increase in the migrant's sense of belonging towards their parental 'home' and their adopted 'home'.

Finally, the last manner in which scholars under the second school of thought believe repatriation helps to strengthen one's sense of belonging to a 'home' is an extension of the last justification; transcendence. When a migrant is repatriated, they are forced to go through an adaptation period where they have to re-assimilate and re-learn behaviors relevant to the social and cultural spheres of their 'home' (parental or adopted) (Ralph \& Staeheli 2011, 524). Through the act of this re-assimilation that only occurs due to repatriation, the migrant, or foreigner as Julia Kristeva would say, has to commit matricide of their metaphorical Mother. Only by letting go of certain practices, values, and in some cases even beliefs, can the migrant finally come to belong to a 'home' (or 'homes') on a teleological level. Thus, as Kristeva's theory suggests, by committing matricide of the metaphorical Mother[land] representing a migrant's 'origins', the migrant rids himself of his Otherness (Kristeva 1991, 9). Though this act of matricide does not make the migrant part of the 'us', it merely turns him into a labeled and categorized stranger who is accepted by the adopted home's collective community. Kristeva further details this realization by the foreigner in her theory and identifies it as Melancholia. It is the ultimate realization that 'home' in fact, does not exist, and in that it transcends the migrant into being a fully formed cosmopolitan citizen whereby the individual belongs nowhere, yet everywhere (Kristeva, 1991, 10). Hence, proving that repatriation does indeed increase one's sense of belonging to a 'home', making it something bigger than just a single nation-state or national identity. The sense of belonging to a 'home' then is lived simultaneously; 'here' and 'there'.

While the two camps of scholarly thought mentioned above appear to be at odds with one another and appear mutually exclusive to one another, this is not actually the case. The two camps highlighted here are in fact, mutually supportive. That is, only by applying the trends under both the camps of belonging can we holistically analyse and 
understand the concept of belonging in the context of transnational individuals.

The current research has largely studied the effects of repatriation on mobile youth coming from or living in the West. The research is severely lacking in the context of the Eastern mobile youth who are from the East or those that move within it. Thus, the Middle East being the world's most cosmopolitan region at the moment makes for a very interesting study of these youth in a previously unstudied context. This article looks to fill this gap in the field by analyzing the concept of 'home' among mobile youth growing up in a part of the world that does not perceive 'belonging' as a migrant's right, rather sees it as privilege. It strives to see how in such an environment then, transnational individuals form their identities and attachments to 'home', more specifically to which 'home' (adopted or parental). In short, do mobile youth feel more attached (or detached) to a 'home' over the other or do they simply have different attachments towards their 'homes'?

In addition to that, this article also hopes to find if prior research findings can be generalized to the Middle Eastern context as well, and vice versa.

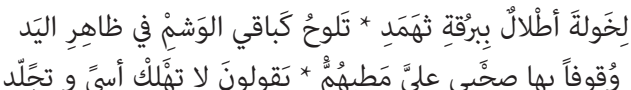

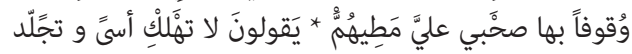

The ruins Khawlah left

on the mottled rockplains of Thahmad

appear and fade, like the trace of a tattoo on the back of a hand.

There my friends halted

tall camels over me,

saying: don't lose yourself

in grief man: endure!

- Mu'allaqah of Tarafah

\section{Theoretical Framework: Belonging Over Identity}

The use of 'identity' as a means to conceptualize a migrant's sense of belonging to a collective identity is a weak method of approaching and understanding a migrant's sense of belonging. Identity as a concept itself is rather malleable and thus, possesses the danger of being an "overarching explanatory framework" towards understanding the migrant's sense of self in relation to the collective (Jones \& Krzyzanowski 2011, 38). As Brubarker and Cooper state, "conceptualizing all affinities and affiliations, all forms of belonging, all experiences of commonality, connectedness, and cohesion, all self-understanding and self-identification in the idiom of "identity" saddles us with a blunt, flat, undifferentiated vocabulary" $(2000,2)$.

Therefore, assessing a migrant's self and its relation to their sense of belonging within a collective identity then should be assessed through the lens of belonging itself. Belonging not only helps to provide a critical assessment of the concept of identity but it can also be utilized as a method to develop more comprehensible and context-sensitive theoretical models as the one created by Jones and Krzyzanowski (2011) (Figure 2). Models as such provide an avenue for a "conceptual unpacking" of the migrant's identity. By using this model, a migrant's sense of belonging can be understood and analyzed through the study of the relationship between three main variables: identity, attachment, and belonging itself. In this way, social scientists are enabled to capture the intricacy and multiplicity of a migrant's self in a manner that may arguably not be possible to do with the use of 'identity' alone as the underlying framework $(2011,38)$.

By making use of the model provided by Jones and Krzyzanowski (2011), one can easily assess the various patterns of a migrant's sense of belonging as the model allows us to assess how these patterns are constructed, and where the migrants position themselves in relation to both their 'parental home's' and their 'adopted home's' collective identities and societies. Through this model we will be able to analyse an array of attachments, preferences, memberships, and feelings to analyse how they collectively add to the sense of belonging of the migrant. This model also makes it possible for us to account for cultural, symbolic and nostalgic dimensions of what may be responsible for holding a collective identity together $(2011,44)$. Furthermore, the theory of belonging outlined within the model theorizes that identities are both internally and externally formed. Internally, migrants are able to position their self and the "(re)presentation" of their self in alignment with those present around them in their collective identity. Externally, the migrant positions their self and sense of belonging within the bounds constituted by an institutional gatekeeper who is capable of enforcing a threshold criterion either formally (i.e. citizenship requirements) or informally (i.e. symbolic "everyday" habits) to control the entry of those from the out-group into the in-group through the process of granting or withholding membership. The model also indicates the many routes that one can possibly take to reach a sense of belonging to a single or multiple collective identity or identities, as well as, the many ways in which one can interpret their understanding of said collective identities (Jones \& Krzyzanowski 2011, 45-46). 
Borders in Globalization Review | Volume 1 | Issue 1 | Fall 2019

Hashmi, "Mobile Youth and Belonging in the Gulf"

The concept of 'belonging' within the Jones and Krzyzanowski model (2011) is not based upon 'objective' outwardly similarities that may exist within the collective identity. Rather, 'belonging' in this model bases itself within a more transitory sense of solidarity among the collective identity (or identities). The model also deeply roots itself into attachments that strengthen or weaken one's sense of belonging to a collective identity. But under this model, old attachments can be replaced with newer attachments or can also be supplemented by other completely different forms of attachments (2011, 46). Thereby, making the relationship between belonging and attachments that much more complex and dynamic. These attachments can also be contradictory to one another as attachments are based on the social actions of the individual (the migrant or the in-group member) and are therefore, fluid. The development of the sense of belonging also mimics a similar pattern. Negative information and perceptions (attachments) are rejected while the positive experiences and interpretations are accumulated to build up strictly positive information about the source of attachments of one's sense of belonging while simultaneously excluding all those that stand to be seen as negative information or experiences as they may weaken or distort the accumulation of the positive information (Jones \& Krzyzanowski 2011, 47).

At a lower level of belonging, the migrant can choose to be included or aligned with the collective identity if their attachments that do not require them to get authentication or authorization from the in-group itself. Migrants aspire to be part of a collective identity (this can be a national or more local identity). So, after surpassing the lowest level of belonging, the migrant must now win the recognition of the 'us' to make it out of their out-group, the 'them'. Even within the members of the in-group there often exist varying levels of membership (residence permits, permanent residence, citizenship, etc.) which further underlines the differences present within the in-group itself that is often portrayed as being a collective of stable and comprehensible identities. However, denial by the in-group of the recognition sought out by the migrant can lead to discrimination or exclusion of the migrant from the in-group's collective identity. Failure to gain membership into the in-group's collective can also have substantial effects on how the migrant then comes to understand their identity and sense of belonging in relation to the identity of the collective itself. While migrants may share similar backgrounds, circumstances, and environments, they may still form two opposing senses of belonging to the collective in question (Jones \& Krzyzanowski 2011, 48-50).

In addition to this model, studies done on the rela- tionship between language and culture will also be made use of briefly to analyze and assess the data collected. Many studies (Earle, 1969; Chiu 2011; Ross, Xun, \& Wilson 2002; Sussman \& Rosenfeld 1982; Trafimow, Silverman, Fan, \& Law 1997; Whorf 1956) on language and culture show, time and again, that people use language as way to encode their experiences, thoughts, and behaviors. As a result, when migrants share a language with the in-group, it allows the migrant to become a part of the in-group much more easily compared to those that do not share the language with the in-group. This is because language encodes in it experiences, and a shared language then conveys shared experiences of the culture more easily to those that speak it as each language has distinct lexis that helps to communicate certain experiences rapidly, consistently, and precisely (Chiu 2011, 8). Those that speak more than one language are also able to effortlessly code-switch socially and culturally compared to those who are monolingual as they code their experiences and thoughts in various languages (Chiu 2011, 9). Given that all participants of this research were at least (fluently) bilingual, this additional lens will only help to deliver a better and more thorough analysis of the interviews when used in conjunction with Jones and Krzyzanowski's theory of belonging.

\section{Analysis: Inside the Mind of a Wanderer}

Moving on from theory to the findings of the interviews, a few identifiers begin to emerge. Upon analyzing the responses of the participants of both Group A and B, the following identifiers surfaced, making the participants' dissociative sense of belonging to 'home' tangible:

i. An informal sense of belonging stemming from the 'duration' of time spent in the adopted or parental 'home'

ii. A formal sense of belonging (acceptance from locals and legal acceptance), or lack thereof, formed in the adopted or parental 'home'

iii. The degree of voluntariness of the participants' movement within the 'homes', and

iv. Spoken languages

These identifiers and their impact on the formation of a sense of belonging towards a 'home' will be analyzed in this section in that order to better understand the mobile youth and their belongingness to 'home.'

\section{Where are you from?}

Arguably, the most difficult question for a mobile child to answer is one strung together by four seemingly simple words, "Where are you from?". I chose to open my interviews with this very question to see 
how the participants would react without having any context to the question. This resulted in lengthy answers instead of straightforward ones as anticipated. Instead of simply saying, "I am French", "I am Belgian-Lebanese", "I am Indian", the participants chose to explain in detail who they were in relation to their unique journeys, even though none of them were ever asked to do so. For a simple question with no context before it, they gave extensive answers to a complete stranger, and did so without knowing the pretext of the research being conducted either. They detailed the durations of their time spent in a particular place, and even made notes of repatriations that took place along their journeys.

Leyla: I am Lebanese but I was born in Kuwait. And I lived there until 2005. And then I moved to Dubai, till 2014. So, I stayed in Dubai from 2005 until 2014. And then I moved to Lebanon. From... like I spent a year in Singapore in 2015. And in 2015 I moved back to Lebanon. And then, once I came to France, like for my university, my family then moved back to Dubai.

Even though they did not 'originate' from every place that they listed in their answers, they identified with those places as where they were from; simply for the fact that they had been there, they had lived there, and grown up there. They subconsciously acknowledged that they do not belong to a singular place, rather they see themselves as belonging to various places. They made their dissociative sense of belonging to 'home' known from the very beginning of the interview by answering a question regarding their 'origins' with a mixed mention of their 'parental' and 'adopted' homes. By using the sense of belonging model in this context then, it becomes clear that the mere attachments that these mobile youth forge towards the countries were in relation to their travels and the duration of time spent in those countries. They were able to form these attachments (and from them their sense of belonging to their 'homes') as they did not require any approval or endorsement from the local in-groups or formal gatekeepers at this level of their membership to the collective (Jones \& Krzyzanowski 2011, 48).

Yet another interesting thing to note is how the participants made a differentiation between where 'they' were from and where their 'parents' were from while answering this question. They actively made a distinction between the journeys of their parents and those of their own, almost unknowingly distancing themselves from the label they knew would be associated with them at first glance. This information too was shared voluntarily, unprompted by any additional questions or cues. Their responses made it clear that they did not derive their sense of belonging to a place (and the sense of belonging of their self) solely from that of their parental heritage, but also from the sheer mobile nature of their lives.

Arjun: My parents are from India. But I never lived there myself. My parents have lived in India their entire lives but they moved to Oman in $1997 / 1998$ for work. I was born in Muscat, Oman in 2000, and moved to Sharjah in UAE, in 2006. And I moved to Dubai in 2009.

An additional layer that helps to show that the attachments forged by these mobile youth to their many countries of residence are not superficial is the manner in which they differentiate between the places they are 'from' and the places they have 'been' to. All the participants had travelled across at least two continents yet, they did not refer to places like Vietnam, Australia, Mongolia, or Italy as 'home'. All participants made a clear distinction between the places they had travelled to and those that they had inhabited. Thus, making it clear that their attachments to their countries of residence are real, and to a large extent temporal, not superficial.

To further clarify this distinction and to get a better idea of what it takes for a place to become 'home', each participant was then asked, in several ways throughout the interview what it was that made them feel at home somewhere. This was done to compare their understanding of a 'home' against their understanding of where they come from.

The participants were first asked to identify their favorite things about their 'adopted home', Dubai. The answers of the participants were similar to one another in spite of them belonging to Group A or B. They singled out the three following favorite things about their 'adopted home':

i. The ease of life and quality of life provided by Dubai.

ii. The safe and secure environment provided by Dubai; and

iii. The diverse and international environment provided by Dubai in which they had the opportunity to grow up.

These responses highlight attachment(s) of the mobile children to their 'adopted home'. They show that their attachments are not solely temporal, they go beyond that. Their attachments also stem from their lived experiences in Dubai. It is through these attachments then that they allot a sense of belonging to Dubai. The first layer of their attachments was evidently an economic one. The improvement of their quality of life from their 'parental home' was a factor for their own parents to move in the first place, and it then became something that was translated down to the mobile youth. Better economic and financial opportunities 
Borders in Globalization Review | Volume 1 | Issue 1 | Fall 2019

Hashmi, "Mobile Youth and Belonging in the Gulf"

gave these mobile youth more freedom to pursue careers and education of their choosing, creating an attachment to Dubai as a 'home' as it became the cradle where they began crafting their futures. An additional layer that then stems from their residence in Dubai was forged through mundane life practices such as schooling, going to malls with friends, or seeing the opening ceremony of BurjAl-Khalifa (the Khalifa Tower, standing over 800 meters tall) with their family. These youth created and collected memories during their residence in Dubai. They networked and forged bonds that go beyond soil and man - they bonded with the people. So, Dubai for them no longer remains a country with the tallest building in the world, it becomes a 'home' because they forge communal ties in it and through it - friendships, enemies, and networks. Further deepening their attachments to the country, one person at a time.

Remy: Even if I was born in France, for me, my real home was Dubai for me. I grew up in Dubai and I remember saying that to my Mum, I remember saying that, "Mum, for me, I come from Dubai and even if I'm not born here, I have all my friends here."

Fynn: The longer I was away from Germany the less it felt like home and the more Dubai had become home (...) even now, when I go back to Dubai it feels like I am going home even though I am not.

Similarly, the participants were asked to identify their favorite things about their 'parental home'. Once again, their responses were similar to one another's in spite of them belonging to Group A or $\mathrm{B}$, or different nationalities. All participants recalled nostalgic memories of summer vacations spent with family and friends, by the beach or food stalls with no responsibilities and duties - only freedom and carelessness. Participants recalled their 'parental homes' as celebrations of Christmas, Eid, Three Kings Day, and many other festivities. If they ever failed to go to their 'parental homes' for the observance of such holidays they celebrated them in Dubai, some even celebrating the Lebanese Independence Day (albeit a minority in the sample). This maintenance of bonds to their 'parental home' further solidified their existing attachments to it as their ancestral home, with their parents acting as their prime and formal link to that 'home.' These attachments to their 'parental homes' then paint more a picture of what Said calls reminiscing of 'paradise lost' (2010, 1386-1387) whereby the mobile youth remember their 'parental homes' in a very specific context outside of which, they would not be inclined to make a 'home' out of them, and most participants openly admitted as much.
Leyla: I really don't think Lebanon is a good place to have a... I always think where I am going to have my career is where I am going to have my kids and where I am going to live with my family. And I wouldn't want my kids to grow up in Lebanon. I would much prefer [for] them to grow up in Dubai.

Although, Remy, and Arjun hesitantly mentioned their 'parental home' as being a place where they would like to settle were no worldly obstacles in their way. Adding that even while there, they would need a more cosmopolitan and international environment to truly feel at home. Lulu, more assuredly expressed similar sentiments but also admitted the harsh reality of the fact that such a Lebanon did not realistically exist for her to return to, and that she could instead apply herself better somewhere in Europe or the Gulf.

The only exception to this was Noha who was glad at the prospect of settling in one of her 'parental homes', Munich. However, she too only preferred Munich due to the diversity the city facilitated. She noted that living in Munich one could never be made to feel like the out- group as those in the 'in-group' were eager to know and acknowledge those different from them. Thus, in Noha's case, the diverse environment of her 'parental home' made her want to make a 'home' out of it. Thus, maintaining the idea of 'home' as being a mix of multiple worlds for mobile individuals to feel at 'home'.

Noha: In Munich, where we have like all the angry Southern Germans, we could still find, a local Turkish community if you're Turkish (...) you can find your nationality everywhere. And they will accept you and the other groups aren't go[ing to] come in your way. Some of them are even go[ing to] be super interested in you. And I really liked that.

\section{Hold the Gates}

Our theoretical model states that attachments can often contradict one another and can sometimes even contradict the sense of belonging of one's own self (Jones \& Krzyzanowski 2011, 42). It is then important for us to assess if any such contradictions do, in fact, exist among our pool of participants. In order to do this, the participants were asked to identify how they felt about having to repatriate from Dubai. This question proved interesting as it revealed the multifaceted nature of the attachments that the mobile youth bore towards Dubai as their 'adopted home'. To answer this question, most of the participants of both Group A and B, responded neutrally saying that they never expected to live in Dubai permanently. They very clearly stated that the very nature of finding a 'home' in the Gulf came 
with the understanding that 'home' would always only ever be temporary.

This belief stems from the fact that the UAE lacks naturalization procedures for expat families settled in the region. Most of the participants, and their parents had been settled in Dubai (or in some cases still remain settled in Dubai at the time of writing) from anywhere between 10 to 18 years. Yet, the formal threshold has never been made accessible to them or their families by the gatekeepers. Thus, hindering the development of the mobile youth's sense of belonging to Dubai as their 'home' to a higher level of membership. Mobile youth, in the context of UAE's laws, are often left out of the picture as they are perceived by the country as being transitory.

Noha: It makes me feel like... like Dubai is not my permanent home (...) Maybe that also contributes to the fact that I don't feel like it's a home because like I could be kicked out of there at any moment.

Failing to overcome the formal thresholds set by the gatekeepers (immigration and naturalization services) of the UAE, the mobile youth then experience a contradiction in their attachment to their 'adopted home'. As they are denied the right to earn a formal membership to the collective, they begin to feel barred, and in that process the youth, as Leyla phrases it, experience a very particular "detachment" from Dubai. That is, they still feel a sense of belonging towards Dubai, but on a level much lower than what they could potentially form had they been allowed into the formal fold of its membership. Thus, while the mobile youth remain willing to see Dubai as a 'home' the system in place prevents them from fully immersing into their sense of belonging to that very notion. Thus, their attachments and belonging then, remain on an informal level of membership and do not develop beyond that level (Jones \& Krzyzanowski 2011, 50), making Dubai feel temporary yet 'home,' at the same time.

\section{I, Volunteer!}

Remy and Leyla, had to perform involuntary repatriations at a young age, in the middle of their schooling. They recall their first repatriations as being times where they felt like something unfair was being done to them. Leyla even used the word "torture" to describe her emotional turmoil at the time of her repatriation.

Leyla: I felt very upset. I was very actually angry at our parents that they were doing this to us.

Remy: I was sad and scared of going back to France because I didn't know what to expect. I didn't know who I was going to meet.

This sense of otherness felt by the two of them took root due to the lack of their personal attachments to their 'parental homes' at the time. Remy had moved at the age of two to Dubai, and Leyla was born in the Gulf. The only attachment they had to their 'parental homes' were perfect summer vacations without any obligations of doing homework or chores. The dispelling of this very fantasy is what hindered their adjustment upon repatriation. It is what is called reverse culture shock (Yuval-Davis 2006, 202). Without having the opportunity to prepare themselves for the changes to come in their 'parental home' is what caused them to panic as they suddenly found themselves outside of their safety blanket, without friends and familiarity, feeling lost and alone.

Eventually, Remy and Leyla did manage to settle into their 'paternal homes' and in fact, grew to like them with time. In Remy's case, this only occurred upon the second repatriation, one that he performed willingly to pursue his undergraduate studies. He chose to move to a small town in France, Menton, with the total student population of 300 and 49 nationalities on campus. It was polar opposite of the local French school he had to fit into upon his first repatriation. For Leyla, the assimilation finally sunk in when she realized that the Lebanese in Lebanon were not that different from the way her parents had raised her to be Lebanese herself. She said,

Leyla: We were very similar because we had the same values, as my parents raised me in a very Lebanese way.

Therefore, while it took a multicultural environment for Remy to begin to feel at home in his "parental home,' for Leyla the assimilation was only made possible due to the link preserved by her parents through the observance of Lebanese cultural and traditional practices while living in Dubai.

Furthermore, Remy's case vividly highlights the importance of voluntariness. The second repatriation that he performed was done so willingly by him and he admitted that that played an imperative role in him feeling at 'home' the second time around. This makes sense as with voluntary movement, mobile youth gain charge of choosing where to go and therefore, have time to not only prepare but also carefully select a place that would suit them best. Whereas, when moving involuntarily, they are more vulnerable to not feeling in control of what is directly happening to them, causing them to experience anxiety and reverse culture shock.

Similar to Remy and Leyla, others like Hachim and Arjun, had similar feelings of not fitting in in their 
Borders in Globalization Review | Volume 1 | Issue 1 | Fall 2019

Hashmi, "Mobile Youth and Belonging in the Gulf"

'parental homes' upon repatriation and they too expressed that losing the power to decide where and when they would move hindered them from feeling fully at home even in their 'parental homes'.

Hachim: You do feel like a little bit out of place and yeah you feel a bit treated differently. Like I lost my accent when I was speaking Moroccan like people were noticing that I wasn't living there and it became worse over time but I got used to it (...) I remember I was in shock and I remember I was mad at my parents for pushing us to leave again.

\section{Speaking in Tongues}

As mentioned under "Theoretical Framework", there is yet another lens to which these mobile youth lend themselves to, and it is that of language. All participants interviewed for this research were at the very least fluently bilingual or multilingual, with some like Leyla, speaking up to six languages at the age of only 20. These youth then become even more intriguing to study as they are not only a cocktail of journeys in terms of the physical distances that they have amassed but also because they unknowingly become keepers of cultures that they do not always have full ownership of.

Basil: I can't say I identify with English. No, I understand and I can communicate [in it] but I don't think I identify with it.

In light of the studies done on language and culture, we know that individuals use language to encode their experiences, thoughts, and behaviors (Earle 1969; Chiu 2011; Ross, Xun, \& Wilson 2002; Sussman \& Rosenfeld 1982; Trafimow, Silverman, Fan, \& Law 1997; Whorf 1956). Therefore, a shared language among a collective can then help to convey shared experiences of the shared culture much more easily to those that speak similar languages (Chiu 2011, 8). Furthermore, individuals fluent in multiple languages have the added advantage of codeswitching in social and cultural contexts, more efficiently than their monolingual counterparts (Chiu 2011, 9). This is perhaps because their minds are already well-trained in thinking in multifaceted ways that this practice becomes second nature to individuals like our participants - making them multicultural and open-minded. It is also this very ability of code-switching that makes mobile youth adaptable to their ever-changing 'homes'.

At the very end of the interview, the participants were asked to identify what 'home' meant to them, and if there was a physical place that they associated to that notion. The participants, yet again, giving similar answers, attached their sense of belonging to a 'home' in relation to people, memories and feelings, and not to a particular 'physical' place with the exception of one participant, Lulu. While Lulu did attach her notions of 'home' to the actual house she grew up in in Dubai, she only saw that house as a 'home' in relation to the memories that were made in it. Therefore, Lulu too did not derive her notion of 'home' from a physical place, rather the house derived its meaning of 'home' from the memories that Lulu made there as a child.

The study of language and culture provides an explanation for this phenomenon. It states that as the minds of the mobile youth are accustomed to discerning every situation through multiple cultural lenses, they are then unable to fully claim ownership of a single culture or place as they are able to easily switch in and out of their many learned 'adopted cultures', making them feel at 'home' everywhere yet nowhere (Whorf 1956, 257). This is made even more complicated when you take into account the fact that our participants identified multiple languages as being their native tongues (most commonly Arabic and French). Thus, Participants of Group A and B struggled to answer when asked to identify a single place in which they would like to settle indefinitely, showing that those with a nomadic upbringing are more likely to continue to pursue such a lifestyle well into their adulthood. Perfect examples of this would be Lulu, and Noha pursuing to practice law in multiple jurisdictions, and Arjun looking to settle in a diverse and cosmopolitan concrete jungle should the time to settle ever arrive.

Thus, in their relationship towards both their 'adopted' and their 'parental' homes, the mobile youth maintained a nomadic outlook on their identity and sense of belonging to not just one of those two homes, rather to all homes that they have had the occasion to traverse. This also explains why then these youth prefer the lifestyle of wandering over settling as their entire thought process has been rewired (Chiu 2011, 13) to better suit a mobile lifestyle, giving rise to their complex understanding of 'home' as 'homes'.

Basil: Home now, the definition... and that's why I believe I have many homes... it's not about a place in particular and I think it's rare to have a place... home is really where your heart is, in the broader sense of things. I believe that everywhere where I have people that I care for can somewhat qualify as my home.

Hachim: I think being at home... maybe a sense of security - a sense of belonging -

Interviewer: So where do you derive this sense of security and belonging from?

Hachim: Umm... the people. 


\section{Discussion}

This article has made an effort to demonstrate the mixed nature of mobile youth's sense of belonging to a 'home' through the application of Jones' and Krzyzanowski's model of "Theory of Belonging" in conjunction with studies of language and culture. As we have observed in the analysis above, mobile youth from both Group A and B bear striking similarities despite their differences in terms of repatriation and even nationalities. This then provides strong evidence for the fact that these youth are even more so shaped by their journeys than initially anticipated by this study. It demonstrates that due to the sheer movement and length of their stays the mobile youth form attachments and a sense of belonging towards multiple homes over a single one. Having said that, there was one slight manner in which the two groups did vary on the topic. Group A, those still settled in Dubai, appeared to hold more skeptical and critical views about Dubai. Whereas Group $B$, those who had returned to their 'parental homes' or moved away from Dubai, appeared to attach more nostalgic notions to the country. This is particularly interesting to note as it appears that upon repatriation the former 'adopted home' transforms and becomes akin to the 'parental home'. It does so as the attachments forged towards it become a product of the act of reminiscing. Dubai, upon repatriation, turns into an encapsulation of paradise lost and is then only remembered as it were in a specific time period. This causes those in Group B to have an increased sense of positivity towards the country they once called their 'home'.

In Ancient Greek tales like that of Homer's epic, The Odyssey, we find depictions that relay this very meaning and relationship between man, journey and 'home' (soil). Throughout his 20-year long journey, Odysseus endures the consequence of many a mistake and equally as many adventures, all to get to Ithaca - to his son and wife. Only, the epic never stops upon Odysseus' arrival at Ithaca. Instead, Homer concludes with a chapter in which Odysseus begins yet another journey. It is as if the nostos "homeland" is carved from the word "nostalgia", the unyielding desire of wanting to return 'home' as one remembers it. Thus, it is only upon his 'homecoming' that Odysseus (the Voyager) realizes that 'home' no longer exists, at least not in the form he reminisced. Hence, at the very end of the epic, Odysseys sets sail in search of 'home', yet again. Homer through his epic seems to be claiming that people at their very core are "nomads", wanders and mobile by nature. As time passes, and more and more journeys are undertaken by the voyager, civilization will eventually espouse a new sense of 'home'.

On the other end of the same spectrum, the Arabs told a tale similar to that of the Greeks. The Arabs, also with the use of poetry, demonstrated a tragic, yet powerful relationship between 'home' and man with poems that not only recognize change, but also grieve and adapt to loss in relation to recurrent departures. Al-Wuquf 'Ala Al-Atlal translating to, "Standing by the Ruins of the Encampment", is a time-old tradition among Arab poets preluding the poems of the Jahiliya times (the 'Age of Ignorance' preceding Islam).

In these poems, poets describe the pain of watching caravans of a beloved's tribe depart. The motif of the poems concern a wandering Bedouin who comes across a ruin, al-atlal, of a former campsite and is overcome by the memories of what once was 'home'. The word wuquf has dual meaning, "standing" or "stopping", depending on the context it is used in. In this context, it is intentionally used in a way that it carries both its meanings simultaneously to depict that this part of the poem reflects the pondering of the Bedouin in his moment of stillness - in his moment of remembrance of 'home'. Hence, he "stops" and "stands" as he ponders over what once existed at that campsite. This tradition arose from the nomadic nature of the Arabs who were accustomed to setting up camps in the desert; un-pitching them, and pitching them elsewhere and then repeating the process throughout their nomadic journeys. Hence, the nod to recurrent departures in the poems. This reminiscing is not one only of sadness, rather it is merely just that reminiscing - a state of nostalgia of a "once upon a time"; a meditative sate of reflection for the wanderer (Cooper 2018).

Similarly, in their relationship towards both their 'adopted' and their 'parental' homes, the mobile youth manage to maintain a nomadic outlook on their identity, and sense of belonging to not just one of those two homes, rather to all homes that they have had the occasion to traverse. Much like Odysseus and the Bedouin, these voyagers too only stop to ponder before they move on in search of another home. Not to replace the ones before it, rather to expand and grow their roots as far and wide as their travels would allow them to (Ralph \& Staeheli 2011, 519).

Basil: I don't see how it could make me anxious, just a feeling of growing. If you have more homes, you're growing bigger, in terms of where you are in the world.

\section{Conclusion}

This paper has aimed to highlight evidence to support the hypothesis that mobile youth build their sense of belonging to multiple homes and not a singular home. They form their attachments 
Borders in Globalization Review | Volume 1 | Issue 1 | Fall 2019

Hashmi, "Mobile Youth and Belonging in the Gulf"

towards their 'adopted homes' through the mixture of the duration of their stay and personal lived experiences within the cultural and social sphere of the collective. They form attachments to their 'parental homes' through a mixture of nostalgia, personal lived experiences, and information learned from their 'parental' figures. Thus, it is clear to see that belonging does indeed have multiple layers and facets to it given the environment in which this process takes place, as well as, the people that it takes place through.

This paper has also sought to demonstrate the intricacies behind the identities of mobile youth in the UAE in an effort to highlight a region not as deeply studied in the field of migration (especially in terms of expatriation and repatriation) as others. The UAE's incredibly international composition of populace and their limiting citizenship and naturalization laws alongside it, make for a challenging and revealing study of the region in terms of migration. It provides a unique backdrop to the mobile youth in the region who find themselves torn between the law and the community at 'home'. Feeling like they belong yet also feeling as if they do not. This paper has thus concluded that multiple journeys between 'homes' (including repatriations) lead to the creation of a multi-faceted individual, one that not only comes to peace with their life of mobility, rather actively seeks it, and dwells within it.

\section{Notes}

1 The GCC is a coalition of seven countries: Bahrain, Egypt, Kuwait, Oman, Qatar, Saudi Arabia, and United Arab Emirates.

2 The seven emirates of the UAE are Abu Dhabi, Dubai, Sharjah, Ajman, Ras Al Khaimah, and Fujairah.

\section{Works Cited}

Brubaker, R., and Cooper, F. 2000. "Beyond 'Identity'," Theory and Society 29: 1-47. http://doi.org/chg9wx

Chiang, F. F. T., Van Esch, E., Birtch, T. A., \& Shaffer, M. A. 2018. "Repatriation: What Do We Know and Where Do We Go from Here," The International Journal of Human Resource Management 29/1: 188-226. http://doi.org/ ddkm

Chiu, C. 2011. "Language and Culture". Online Readings in Psychology and Culture 4/2: 1-17.

Cooper, P. 2018. "The Ancient Poems that Explain Today." BBC. Retrieved from: http://www.bbc.com/culture/ story/20180820-the-6th-century-poems-making-a-comeback
Earle, M. 1969. "A cross-cultural and cross-language comparison of dogmatism scores," Journal of Social Psychology 79: 19-24. http://doi.org/d23j6s

The United Arab Emirates' Government Portal. 2019. UAE Nationality. Retrieved from: https://www.government. ae/en/information-and-services/passports-and-traveling/uae-nationality

Guarnizo, L. 1997. "The emergence of a transnational social formation and the mirage of return migration among Dominican transmigrants," Identities 4/2: 281-322. http://doi.org/b6bn52

Jones, P., \& Krzyzanowski, M. 2011. "Identity, Belonging and Migration: Beyond Constructing 'Others'., In G. Delanty, R. Wodak, \& P. Jones (Eds.), Identity, Belonging and Migration. Liverpool University Press: 38-53.

Kristeva, J. 1991. Strangers to Ourselves. New York: Columbia University Press.

Kyle, D. 2000. Transnational peasants: migrations, networks, and ethnicity in Andean Ecuador. Baltimore: John Hopkins University Press.

Minh-ha, T. T. 2010. Elsewhere, Within Here. New York: Routledge.

Ralph, D. \& Staeheli, L. A. 2011. "Home and Migration: Mobilities, Belongings and Identities: Home and Migration," Geography Compass 5/7: 517-530. http://doi. org/dazmg5

Ross, M., Xun, W. Q. E., \& Wilson, A. E. 2002. "Language and the bicultural self," Personality and Social Psychology Bulletin 28: 1040-1050. http://doi.org/c9spnq

Rouse, R. 1991. "Mexican migration and the social space of postmodernism," Diaspora 1/1: 8-26. http://doi.org/ gc9z74

Said, E. 2001. Reflections on Exile. New York: Granta.

Schaffer, F. 2006. "Ordinary Language Interviewing" In Dvora. Y. (Ed.), Interpretation and Method: Empirical Research Methods and the Interpretive Turn. Armonk, N.Y.: M E Sharpe Inc: 187-191.

Schaffer, F. C. 2016. Elucidating Social Concepts: An Interpretivist Guide. New York: Routledge.

Sussman, N. N., \& Rosenfeld, H. M. 1982. "Influence of culture, language, and sex on conversational distance," Journal of Personality and Social Psychology 42: 66-74. http://doi.org/d7hs4j

Trafimow, D., Silverman, E. S., Fan, R. M.-t., \& Law, J. S. F. 1997. "The effects of language and priming on the relative accessibility of the private self and the collective self," Journal of Cross-Cultural Psychology 28: 107-123. http://doi.org/cp8gch

Whorf, B. L. 1956. Language, thought, and reality: Selected writings of Benjamin Lee Whorf. New York: Wiley.

Yuval-Davis, N. 2006. "Belonging and the Politics of Belonging." Patterns of Prejudice 40/3: 197-214. http:// doi.org/fswd5z

Zhang, B. 2004. "The Politics of Re-homing: Asian Diaspora Poetry in Canada (Critical Essay)," College Literature 31/1: 103-125. http://doi.org/cdn5g2 